\title{
Heat Transfer Coefficient of Fluidized Bed and Its Application to Patenting Technique*
}

\author{
By Eiji TAKAHASHI,** Masaru SHIMIZU, ** Yasuhiro OKI** \\ and Osamu ISHIGAMI**
}

\begin{abstract}
Synopsis
In order to improve the drawability of wire and wire rod and to obtain the mechanical properties desirable in drawn wire, the lead patenting has long been applied in practical use. Recently, however, there has been a demand for lead-less patenting on the part of customers who face growing public concern about occupational health and the prevention of pollution. As a means of settling those problems, the fluidized bed patenting method has been researched.

In various conditions of the fluidized bed temperature, air velocity and immersion time in the fluidized bed, experiments on the cooling of heated wire and wire rod in the fluidized bed have been carried out.

Heat transfer coefficient of the fluidized bed is affected by the air velocity, surface condition of the specimen, distance from the distributor, and the type of fluidizing particles. Excellent mechanical properties of the stocks patented in the fluidized bed, as good as those in lead bath can be obtained by optimization of the bed temperature, air velocity and immersion time in the bed. The scattering of mechanical properties and the drawability of the stocks patented in the bed are the same as or betler than those in lead bath.
\end{abstract}

\section{Introduction}

Lead and air patenting processes have long been applied as practical heat treatments of carbon steels in order to improve the drawability of wire and wire rod for such end uses as prestressed concrete strand and wire, springs, wire rope, etc., and to obtain desired mechanical properties in drawn wires.

However, lead patenting is usually accompanied by a number of serious problems concerning plant hygiene and environmental pollution. Because lead bath temperatures have to be kept in the range of about $450^{\circ}$ to $650^{\circ} \mathrm{C}$, the molten lead tends to vaporize, emitting fine lead oxide particles into the environment. Lead oxide in the form of dross is generated in the bath itself and its removal is a fairly dangerous operation. A great care must be taken in disposing the lead bath oxide. A caution must also be exercised in the disposal of the lead-contaminated sand used in wiping the stock clean and of the cooling water.

With these problems in mind, we looked about for other patenting processes and finally concentrated our studies on fluidized bed patenting. As a result of our efforts the patenting of wire rods by this method has been realized on a commercial production basis.

The aim of the present study is to reveal the cooling characteristics of wire rod in the fluidized bed, the mechanical properties and the quality of the stocks patented in the bed.

\section{Materials and Experimental Procedure}

\section{Materials}

Commercial grade wire rod and $2.0 \mathrm{~mm}$ diameter drawn wire were used in this experiments. The chemical compositions of the specimens are shown in Table 1.

\section{Measurement of Cooling Curves and Calculation of Heat Transfer Coefficient}

The following procedures were applied in the measurement of cooling curves. The fluidized bed was $500 \mathrm{~mm}$ long and $300 \mathrm{~mm}$ wide. Zircon sand was used as a medium in the fluidized bed. The average particle size was $0.10 \mathrm{~mm}$. Air was used to activate the fluidizing medium. The air velocity was 3.5 to $18 \mathrm{~cm} / \mathrm{sec}$. The bed temperature was controlled by an electric heater. For the measurement of cooling curve, an alumel-chromel thermocouple was connected to the center surface of the specimen. Also, an earth was connected to one side of the specimen to avoid the influence of electro-motive force induced by

Table 1. Chemical compositions of specimens (wt \%)

\begin{tabular}{|c|c|c|c|c|c|c|c|}
\hline Specimen & $\begin{array}{l}\text { Diameter } \\
(\mathrm{mm} \phi)\end{array}$ & $\mathrm{C}$ & $\mathrm{Si}$ & $\mathrm{Mn}$ & $\mathrm{P}$ & $\mathrm{S}$ & Total Al \\
\hline SWRH $62 \mathrm{~A}$ & 5.5 & 0.60 & 0.19 & 0.42 & 0.011 & 0.015 & tr. \\
\hline SWRH $62 \mathrm{~A}$ & 7.0 & 0.63 & 0.22 & 0.50 & 0.023 & 0.022 & $\operatorname{tr}$ \\
\hline SWRH 62A & 9.5 & 0.62 & 0.22 & 0.42 & 0.015 & 0.018 & $\operatorname{tr}$ \\
\hline SWRH $72 \mathrm{~A}$ & 2.0 & 0.74 & 0.21 & 0.48 & 0.012 & 0.013 & $\operatorname{tr}$ \\
\hline SWRH 72A & 5.5 & 0.74 & 0.21 & 0.48 & 0.012 & 0.013 & $\operatorname{tr}$ \\
\hline SWRH 72A & 9.5 & 0.74 & 0.21 & 0.47 & 0.012 & 0.020 & $\operatorname{tr}$ \\
\hline SWRH 77A & 5.5 & 0.75 & 0.25 & 0.54 & 0.016 & 0.024 & 0.051 \\
\hline SWRH 77A & 7.0 & 0.75 & 0.23 & 0.53 & 0.024 & 0.018 & 0.056 \\
\hline SWRH 77A & 9.5 & 0.75 & 0.24 & 0.54 & 0.013 & 0.026 & 0.053 \\
\hline
\end{tabular}

* Originally published in Tetsu-to-Hagané, 62 (1976), 1373, in Japanese. English version received August $23,1976$.

** Steel Wire Rod \& Bar Development Dept., Iron and Steel Production Division, Kobe Steel, Ltd., Wakinohama-cho, Fukiai-ku, Kobe 651 . 
the heater. The specimen was heated to $900^{\circ} \mathrm{C}$ in the heating furnace and then cooled rapidly in the fluidized bed which had been kept at $50^{\circ}$ to $200^{\circ} \mathrm{C}$.

Cooling characteristics are assessed by heat transfer coefficient between the fluidized bed and immersed stock. Heat transfer coefficient was calculated from cooling curves.

Heat transfer coefficient was analyzed as follows: It is assumed that the distribution of temperature in the internal part of the specimen is negligible because heat transfer rate in the specimen is much larger than that between the bed and specimen, and thermal capacity of the bed is much larger than that of wire rod.

Heat balance of wire rod at a very brief time $d t$ can be expressed in the following equation.

$$
\alpha \cdot(\pi D) \cdot\left(T-T_{o}\right)=\frac{\pi D^{2}}{4} \cdot \rho_{s} \cdot C_{s} \cdot d T / d t
$$

where, $\alpha$ : Heat transfer coefficient

$D$ : Diameter of wire rod

T: Temperature of wire rod

$T_{0}$ : Temperature of the fluidized bed

$\rho_{s}:$ Density of steel

$C_{s}$ : Specific heat of steel

$C_{s}$ and $\rho_{s}$ of steel are usually taken as $0.19 \mathrm{kcal} /$ $\left(\mathrm{kg} \cdot{ }^{\circ} \mathrm{C}\right)$ and $7850 \mathrm{~kg} / \mathrm{m}^{3}$, respectively. Equation (1) is, by integration, rewritten as follows if $T=T_{s}$ at $t=0$, and $T=T$ at $t=t$.

$$
\begin{aligned}
& \alpha=-3.0 \times 10^{4} \log \left(\begin{array}{c}
T-T_{o} \\
T_{s}-T_{o}
\end{array}\right) / t \quad \text { at } 9.5 \mathrm{~mm} \text { diameter } \\
& \alpha=-2.2 \times 10^{4} \log \left(\begin{array}{c}
T-T_{o} \\
T_{s}-T_{o}
\end{array}\right) / t \quad \text { at } 7.0 \mathrm{~mm} \text { diameter } \\
& \alpha=-1.7 \times 10^{4} \log \left(\begin{array}{c}
T-T_{o} \\
T_{s}-T_{o}
\end{array}\right) / t \quad \text { at } 5.5 \mathrm{~mm} \text { diameter }
\end{aligned}
$$

where, units of $\alpha$ and $t$ are $\left[\mathrm{kcal} /\left(\mathrm{m}^{2} \cdot \mathrm{hr} \cdot{ }^{\circ} \mathrm{C}\right)\right]$ and [sec], respectively.

Equation (2) is only applicable to the simple cooling curve. However, as commercial wire rod was used as a specimen in this experiment, generation of the heat is caused by the pearlite transformation in cooling of wire rod from $900^{\circ} \mathrm{C}$. So Eq. (2) is not applicable to cooling curve from $900^{\circ} \mathrm{C}$. In this experiment, Eq. (2) is applied to the temperature range of wire rod below $500^{\circ} \mathrm{C}$; in this range the pearlite transformation comes to the end.

\section{Heat Treatment Procedure}

Wires and wire rods were patented in accordance with the procedure described below.

The wire rod was paid off into a continuous gas furnace where it was heated to $900^{\circ} \mathrm{C}$. It was then cooled rapidly in the fluidized bed which was kept at $100^{\circ}$ to $500^{\circ} \mathrm{C}$. The bed was $3 \mathrm{~m}$ long and $2 \mathrm{~m}$ wide. After cooling, the wire rod was passed through a holding furnace at $500^{\circ} \mathrm{C}$ and then taken up. The holding furnace was $4 \mathrm{~m}$ long and $2 \mathrm{~m}$ wide. The holding furnace was installed just behind the fluidized bed. This arrangement was to simulate the cooling situa- tion of a lead bath as closely as possible.

The fluidizing medium and the fluidized fluid were zircon sand and air respectively, which were the same as those in the measurement of cooling curves. The air velocity was 3.5 to $18 \mathrm{~cm} / \mathrm{sec}$. The fluidized bed was heated by radiant tubes and cooled by water sprays. The bed temperature was detected by a thermocouple, which was immersed in the bed. The variations from the set temperature were controlled within $\pm 10^{\circ} \mathrm{C}$.

The structure of the wire rod patented in the fluidized bed was inspected by an electron-microscope and tests as to mechanical properties and drawability were also carried out on the rod.

\section{Experimental Results}

\section{Heat Transfer Characteristics in Fluidized Bed}

Several papers ${ }^{1-6}$ ) have been published on heat transfer coefficient in the fluidized bed using alumina, ferro-silicon or silicon carbide as a fluidizing medium, and also on the application of the fluidized bed to the use in patenting technique. However, the heat transfer coefficient in the bed using zircon sand as the fluidizing medium has not been reported yet. Yamakoshi, et al. ${ }^{7}$ ) have applied the fluidized bed using zircon sand to the controlled cooling of wire rods immediately after hot rolling, but have little referred to the cooling characteristics.

Figure 1 gives the cooling curves of wire rod in the zircon sand bed. For comparison purposes we have also shown in the same graph the cooling curves for wire rod in molten lead and in air blast of $35 \mathrm{~m} / \mathrm{sec}$. As can be seen, the operating temperature of the fluidized bed must be much lower than that of the lead bath in order to have approximately the same cooling rate from the austenitizing temperature $\left(900^{\circ} \mathrm{C}\right)$ through the transformation temperature $\left(500^{\circ}\right.$ to $650^{\circ} \mathrm{C}$ ) both in the former and the latter.

The heat transfer coefficient calculated from the cooling curves in Fig. 1 and Eq. (2) is approximately $670 \mathrm{kcal} /\left(\mathrm{m}^{2} \cdot \mathrm{hr} \cdot{ }^{\circ} \mathrm{C}\right)$ in the fluidized bed at an air velocity of $12 \mathrm{~cm} / \mathrm{sec}$. In molten lead it is about $3000 \mathrm{kcal} /\left(\mathrm{m}^{2} \cdot \mathrm{hr} \cdot{ }^{\circ} \mathrm{C}\right)$, in an air blast with a velocity of $35 \mathrm{~m} / \mathrm{sec}$ it is approximately $300 \mathrm{kcal} /\left(\mathrm{m}^{2} \cdot \mathrm{hr} \cdot{ }^{\circ} \mathrm{C}\right)$, and in atmosphere it is about $60 \mathrm{kcal} /\left(\mathrm{m}^{2} \cdot \mathrm{hr} \cdot{ }^{\circ} \mathrm{C}\right)$.

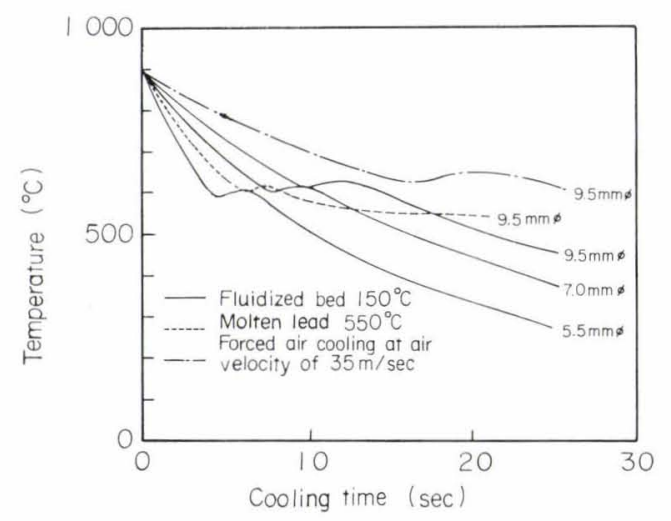

Fig. 1. Cooling curves of wire rods in various cooling medium 
Figure 2 shows the relationship between heat transfer coefficient and air velocity. In this test the surface scale of the test specimen is removed with emery paper in order to avoid the influence of it. The heat transfer coefficient increases rapidly from $300 \mathrm{kcal} /\left(\mathrm{m}^{2} \cdot \mathrm{hr} \cdot{ }^{\circ} \mathrm{C}\right)$ at the minimum fluidization velocity to about 670 $\mathrm{kcal} /\left(\mathrm{m}^{2} \cdot \mathrm{hr} \cdot{ }^{\circ} \mathrm{C}\right)$ at an air velocity of $12 \mathrm{~cm} / \mathrm{sec}$. However, the heat transfer coefficient is nearly constant in the air velocity range over $12 \mathrm{~cm} / \mathrm{sec}$ up to $18 \mathrm{~cm} / \mathrm{sec}$. According to the literature, ${ }^{8,9)}$ the coefficient increases rapidly, over a comparatively narrow velocity range until it reaches a peak and then, decreases steadily. The reason we could not find such a phenomenon may be attributed to that the experiments were not carried out at an air velocity of over $18 \mathrm{~cm} / \mathrm{sec}$. Moreover, Fig. 2 indicates that heat transfer coefficient is independent of the bed temperature, the bed height and diameter of wire rod.

The influence of surface scale on heat transfer coefficient is shown in Fig. 3. In this experiment the surface scales are loose and easily peeled because the specimens were heated in the atmosphere. For comparison purposes we have also shown in the same graph the results obtained on the descaled specimen. In the case of such heavily oxidized surface, the coefficient, though it scatters considerably, amounts to approximately 500 to $600 \mathrm{kcal} /\left(\mathrm{m}^{2} \cdot \mathrm{hr} \cdot{ }^{\circ} \mathrm{C}\right)$ at air velocity of over $12 \mathrm{~cm} / \mathrm{sec}$. This value is smaller than that obtained on descaled specimen. Those results can be attributed to that a boundary layer is formed between loose scale and steel surface, and consequently, the steel surface is not cooled directly by the fluidized bed.

Figure 4 shows a change of the heat transfer coefficient in the vertical direction of the bed. $L_{f}$ indicates the surface of the bed. It is observed that the heat transfer coefficient in the zone from the bottom to about $40 \mathrm{~mm}$ high is smaller than that in the center. It is also observed that the coefficient lowers in the vicinity of the bed surface.

It seems that the presence of such a low heat transfer coefficient area in the vicinity of the distributor results from the fact that the velocity of the fluid is smaller in this area than in the center of the bed, because the bed temperature is lower than the bed center and consequently the mobility of the fluidizing particle is small owing to the small amount of heat exchange between the stock and the bed in this area. It can also be presumed that the transition of heat transfer coefficient in the vicinity of the bed surface is due to a bubbling phenomenon, i.e., a partial exposure of the stock from the bed near $L_{f}$ and a partial crashing of fluidizing particles to the stock above $L_{f}$, which is inherent to fluidized beds.

Heerden, et al. ${ }^{10)}$ and Dow, et al. ${ }^{11)}$ summarized the influence of the fluidized particles on heat transfer coefficient. From their papers it is expected that the size and specific gravity of the particle influence very much on the coefficient. Heat transfer coefficients of the bed using zircon, alumina, silica, and iron powders as a fluidizing medium are measured as shown in Table 2. The heat transfer coefficients of the fluidized zircon sand bed and the alumina sand bed are nearly

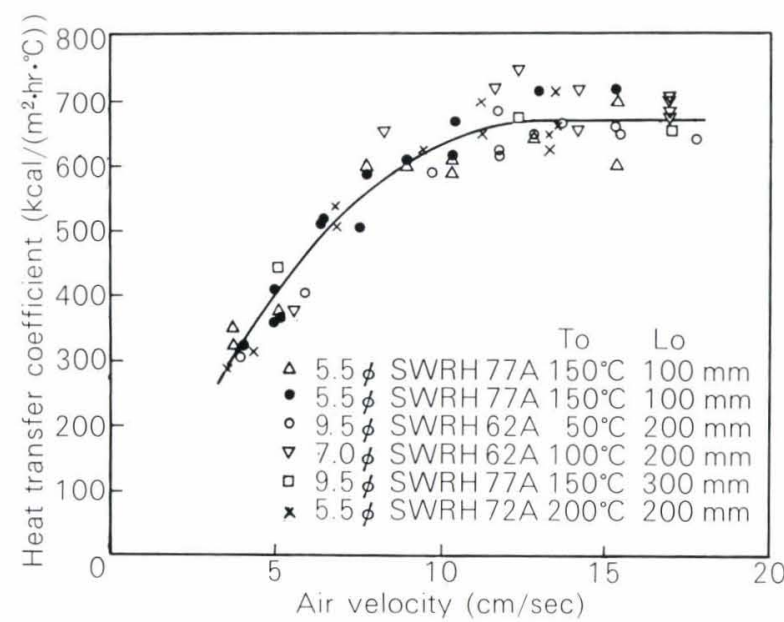

$T_{o}$ : The bed temperature

$L_{0}$ : The bed height

Fig. 2. Influence of air velocity on heat transfer coefficient

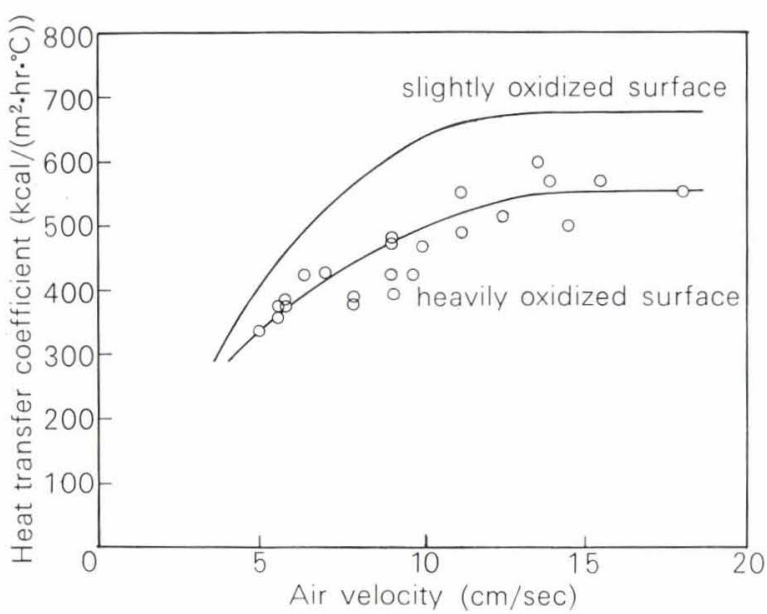

Fig. 3. Influence of scaling condition on heat transfer coefficient

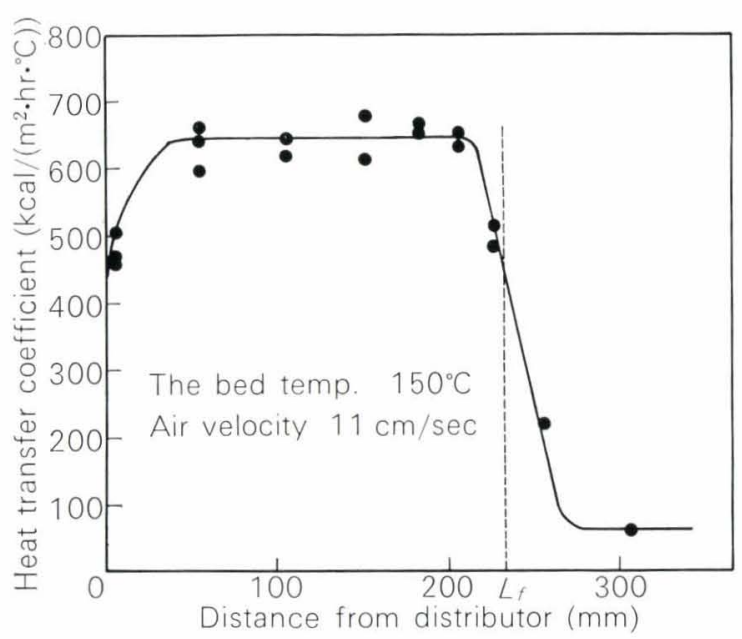

Fig. 4. Influence of distance from distributor on heat transfer coefficient

equal and the coefficient of the silica sand bed and the iron powder bed is also nearly equal. Those results suggest that the particle size is an important factor for heat transfer coefficient of the bed. From the results of the silica sand bed and the iron powder bed, it is apparent that the specific gravity is less important 
Table 2. Heat transfer coefficient of the bed using the various particles as the fluidizing medium

\begin{tabular}{c|cccc}
$\begin{array}{c}\text { Physical } \\
\text { properties }\end{array}$ & $\begin{array}{c}\text { Mesh } \\
\text { number }\end{array}$ & $\begin{array}{c}\text { Specific } \\
\text { gravity }\end{array}$ & $\begin{array}{c}\text { Specific } \\
\text { heat } \\
(\mathrm{kcal} / \\
\left.\left(\mathrm{kg} \cdot{ }^{\circ} \mathrm{C}\right)\right)\end{array}$ & $\begin{array}{c}\text { Heat } \\
\text { transfer } \\
\text { coefficient } \\
(\mathrm{kcal} /\end{array}$ \\
$\left.\left(\mathrm{m}^{2} \cdot \mathrm{hr} \cdot{ }^{\circ} \mathrm{C}\right)\right)$
\end{tabular}

factor than the particle size in determining the value of heat transfer coefficient. The coefficient is higher as the specific gravity is greater. The fluidized zircon sand bed is the most suitable for the patenting of wire rod because the zircon sand bed has the highest value of the coefficient among those beds.

As described above, the heat transfer coefficient of the fluidized bed are primarily affected by the air velocity, surface scale condition, distance from the distributor, and types of the particles. In addition to those factors, it is reported ${ }^{2)}$ that the type of the fluidizing gas is also an important factor. However, we do not report about this factor because it is disadvantageous for the production on a commercial basis to use a gas, other than air as a fluidizing gas.

\section{Mechanical Properties of Stock Patented in the Fluidized Bed}

The mechanical properties of rod and wire patented in the fluidized bed depend largely on the cooling rate from the austenitizing temprature down to the transformation temperature. Therefore, the bed temperature is of crucial importance to the whole process.

Since the heat transfer coefficient between fluidized bed and immersed stock depends on the air velocity, as is shown in Fig. 2, the fluidizing air velocity influences the mechanical properties of the heat treated stock.

Likewise, because the temperature of wire rod coming out of the fluidized bed also influences the mechanical properties, the immersion time in the bed plays an important role in this patenting method.

The relationship between fluidized bed temperature and tensile strength of specimens SWRH 72A in 2.0, 5.5 and $9.5 \mathrm{~mm}$ diameter, patented in accordance with our experimental procedures, is shown in Fig. 5. The air velocity in the fluidized bed is $12 \mathrm{~cm} / \mathrm{sec}$.

The effect of the bed temperature on the tensile strengths of patented rod and wire varies with diameters of the stock. The tensile strengths of the three specimens in 2.0, 5.5 and $9.5 \mathrm{~mm}$ diameter differ by about 10,5 and $2.5 \mathrm{~kg} / \mathrm{mm}^{2}$, respectively, when the bed temperature is changed by $100^{\circ} \mathrm{C}$. As the stock diameter increases, the sensitivity of the tensile strength to fluidized bed temperature decreases.

On the other hand, in lead patenting, a $10^{\circ} \mathrm{C}$ change in the lead bath temperature caused a tensile strength variation of about $2 \mathrm{~kg} / \mathrm{mm}^{2}$ in specimens 5.5 to 9.5 $\mathrm{mm}$ in diameter.

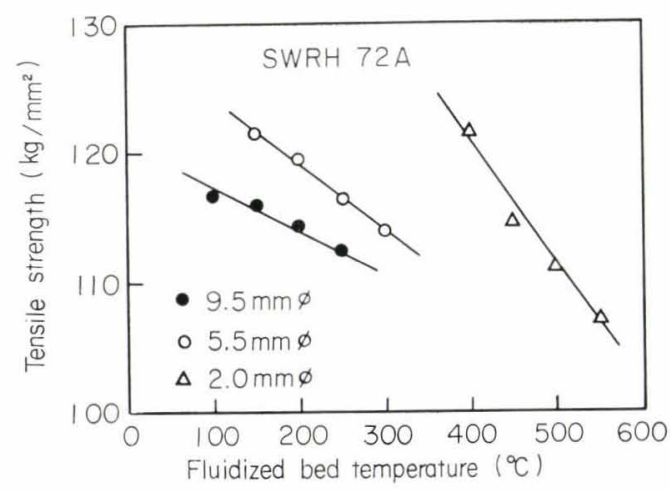

Air velocity: $12 \mathrm{~cm} / \mathrm{sec}$

Immersion time in fluidized bed: $9.5 \mathrm{mmó} 22 \mathrm{sec}$ $5.5 \mathrm{~mm} \phi 12 \mathrm{sec}$ $2.0 \mathrm{~mm} \dot{\phi} 6 \mathrm{sec}$

Fig. 5. Influence of fluidized bed temperature on tensile strength of $0.72 \%$ carbon steel wires and wire rods

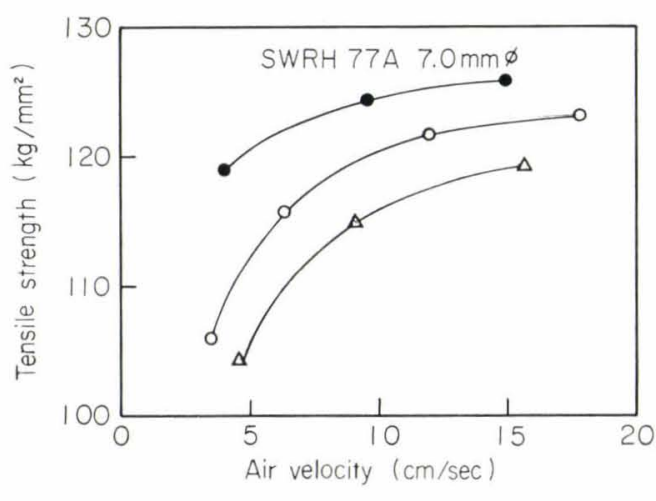

Fluidized bed temperature: - $100^{\circ} \mathrm{C}, 0200^{\circ} \mathrm{C}$, $300^{\circ} \mathrm{C}$,

Immersion time in fluidized bed: $15 \mathrm{sec}$

Fig. 6. Influence of air velocity on tensile strength of $0.77 \%$ carbon steel wire rods cooled at various fluidized bed temperature

Given this significant difference in how temperature changes effect the tensile strength between the fluidized and lead bath patenting processes, it can be assumed that the scattering of mechanical properties of fluidized bed patented stock is considerably less than that with lead patented stock.

To produce SWRH 72A rod and wire with a tensile strength of $115 \mathrm{~kg} / \mathrm{mm}^{2}$, it will therefore be necessary to set the fluidized bed temperature at about $450^{\circ}$, $300^{\circ}$ and $150^{\circ} \mathrm{C}$ for stocks of $2.0,5.5$ and $9.5 \mathrm{~mm}$ in diameter, respectively. Other desired tensile strengths can be obtained by appropriately changing the temperature of the fluidized bed.

Figure 6 shows the effect of air velocity on the tensile strength of patented SWRH 77A wire rod, 7.0 $\mathrm{mm}$ diameter. In this case, the bed temperature is set at $100^{\circ}, 200^{\circ}$ and $300^{\circ} \mathrm{C}$, and the immersion time is $15 \mathrm{sec}$. The tensile strength of patented rod rises sharply in the range over the minimum fluidization air velocity of $3.5 \mathrm{~cm} / \mathrm{sec}$ to an air velocity of $12 \mathrm{~cm} / \mathrm{sec}$ but over an air velocity of $12 \mathrm{~cm} / \mathrm{sec}$ it shows only a slight increase. This phenomenon appeared in similar fashion at any temperature during the experiment. 
Moreover, this phenomenon corresponds to the relation between heat transfer coefficient and air velocity shown in Fig. 2.

The influence of immersion time in the fluidized bed on the tensile strength of the stock is shown in Fig. 7. At first, the tensile strength of the patented rod increases in a linear fashion with the immersion time in the bed. Then, after some time, it remains nearly constant. The point at which tensile strength levels off changes with the stock diameter. For SWRH $62 \mathrm{~A}$ wire rod, $5.5 \mathrm{~mm}$ diameter, it lies at around $7 \mathrm{sec}$ at a bed temperature of $300^{\circ} \mathrm{C}$, while, for SWRH $62 \mathrm{~A}$ wire rod, $7.0 \mathrm{~mm}$ diameter, it is about $10 \mathrm{sec}$ at a bed temperature of $250^{\circ} \mathrm{C}$.

Photograph 1 shows the microscopic structures of SWRH 62A wire rod, $5.5 \mathrm{~mm}$ diameter, patented with varying lengths of immersion time at an air velocity of $12 \mathrm{~cm} / \mathrm{sec}$ and a bed temperature of $300^{\circ} \mathrm{C}$. The lamellar spacing narrows with increasing the immersion time in the bed (Photo. 1(a) to (c)) but, after $9.5 \mathrm{sec}$, the lamellar spacing is very fine and constant (Photo. l(c) to (e)). These structures do not contain any free ferrite and they are the same as observed in the lead patented wire rod.

The desired tensile strength can be obtained by optimization of three factors described above. However, it is required that the scattering of patented stock is as small as possible in the production conditions. Therefore, the tensile strength of patented stock is

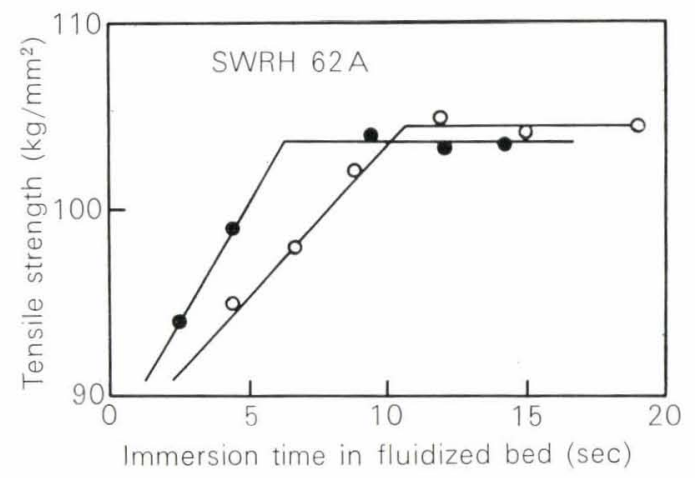

Air velocity: $12 \mathrm{~cm} / \mathrm{sec}$

Fluidized bed temperature: $5.5 \mathrm{~cm} \phi 300^{\circ} \mathrm{C}$ $07.0 \mathrm{~mm} \dot{\phi} 250^{\circ} \mathrm{C}$

Fig. 7. Influence of immersion time in fluidized bed on tensile strength of $0.62 \%$ carbon steel wire rods controlled by the change of the bed temperature because of the excellent uniformity in the bed temperature. On the other hand, an air velocity should be fixed in the range of 12 to $18 \mathrm{~cm} / \mathrm{sec}$, in this range the tensile strength is nearly constant even if the air velocity is subject to some change. Moreover, it is favorable that the stocks should be patented in the range of immersion time in which tensile strength is constant.

The influence of carbon equivalent on the tensile strength in patented wire rod is shown in Fig. 8. The carbon equivalent employed in this experiment was $\mathrm{C}_{\mathrm{eq}}=\mathrm{C}+0.2 \mathrm{Mn}(\%)$. Wire rod as shown in Table $\mathrm{l}$ as well as other grades (not shown) are used. $5.5 \mathrm{~mm}$ diameter stock is patented for $12 \mathrm{sec}$ in a bed temperature of $300^{\circ} \mathrm{C}$ and an air velocity of $12 \mathrm{~cm} / \mathrm{sec} .9 .5 \mathrm{~mm}$ diameter stock is patented for $22 \mathrm{sec}$ in a bed of $150^{\circ} \mathrm{C}$ with an air velocity of $12 \mathrm{~cm} / \mathrm{sec}$. The solid line in Fig. 8 represents the general tensile strengths of lead patented rod. As can be seen, the tensile strengths resulting from our experiments fall very close to the solid line.

We installed a water spray to limit the increase of the bed temperature caused by heat from the enter-

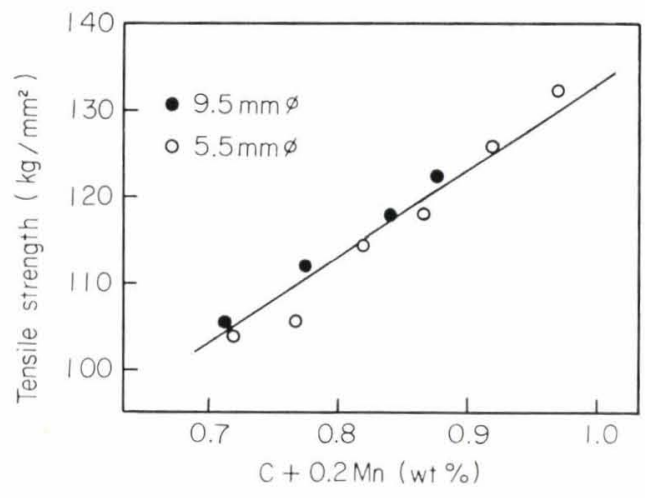

Air velocity: $12 \mathrm{~cm} / \mathrm{sec}$

- 9.5 mmó

Fluidized bed temperature $\quad 150^{\circ} \mathrm{C}$

Immersion time in fluidized bed $22 \mathrm{sec}$ $5.5 \mathrm{~mm} \dot{\phi}$

Fluidized bed temperature $\quad 300^{\circ} \mathrm{C}$

Immersion time in fluidized bed $12 \mathrm{sec}$

Fig. 8. Relation between $(\mathrm{C}+0.2 \mathrm{Mn}) \mathrm{wt} \%$ and tensile strength of wire rods. Solid line is usual aimed value in lead patenting.
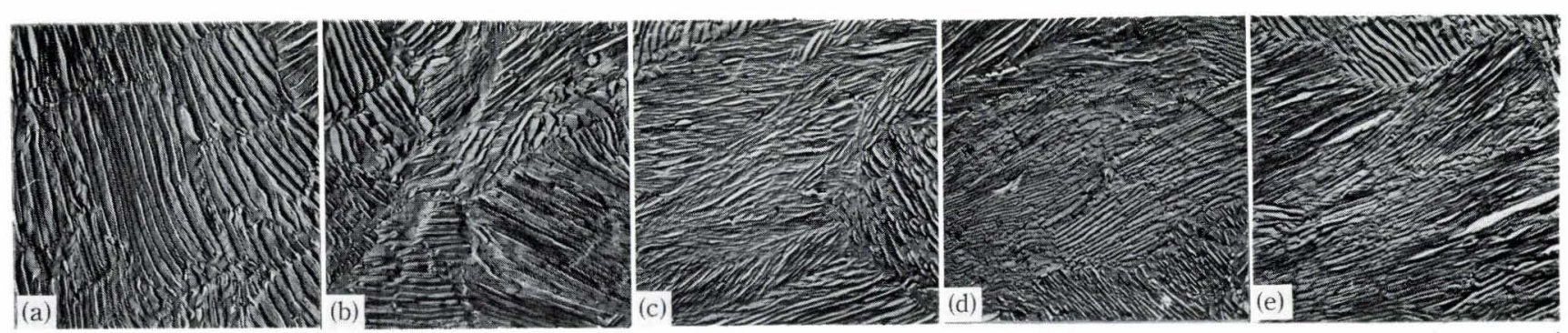
$\begin{array}{lrlll}\text { Immersion time: } & \text { (a) } & 2.5 \mathrm{sec} & \text { (b) } 4.5 \mathrm{sec} & \text { (c) } 9.5 \mathrm{sec} \\ \text { Air velocity } & 12 \mathrm{~cm} / \mathrm{sec} \\ \text { The bed temperature: } & 300^{\circ} \mathrm{C}\end{array}$

(d) $12 \mathrm{sec}$ (e) $14 \mathrm{sec}$

Photo. 1. Electron replica micrographs of $0.62 \%$ carbon steel wire rods patented in various immersion time in the fluidized bed 
ing stock and the water evaporation phenomenon was used to control the bed temperature. In this case, the control range of the bed temperature was above $100^{\circ} \mathrm{C}$.

Patenting SWRH 72A wire rod, $11.0 \mathrm{~mm}$ diameter, by this method at a bed temperature of about $110^{\circ} \mathrm{C}$, we found the tensile strength of the stock to be 114 $\mathrm{kg} / \mathrm{mm}^{2}$.

Wire of $1.0 \mathrm{~mm}$ diameter was patented in the same way at bed temperatures of between $450^{\circ}$ and $550^{\circ} \mathrm{C}$.

The possibility of fluidized bed patenting of wire rod and wire in the diameter range from 1.0 to 11.0 $\mathrm{mm}$ was thus ascertained.

\section{The Scattering of Mechanical Properties and the Drawa- bility of Stocks Patented in the Fluidized Bed}

Because of the greater uniformity of the fluidized bed temperature as compared to the lead bath temperature, and the smaller influence of temperature on mechanical properties, it is expected that the scatter range for mechanical properties of fluidized bed patented stocks is at least the same or smaller than that of lead patented stocks.

We patented one coil of $400 \mathrm{~kg}$ of SWRH 62A wire rod, $5.5 \mathrm{~mm}$ in diameter, in the fluidized bed and took a total of 141 sample pieces from it at $10 \mathrm{~m}$ intervals.

The distribution of tensile strength values of these specimens is shown in Fig. 9. The mean tensile strength of these samples was $108.1 \mathrm{~kg} / \mathrm{mm}^{2}$, standard deviation $1.2 \mathrm{~kg} / \mathrm{mm}^{2}$, and range of distribution 5.5 $\mathrm{kg} / \mathrm{mm}^{2}$. Again, these values are the same or smaller than those in lead patenting.

These results show again that the scattering of mechanical properties of stock processed by the fluidized bed method is about the same or less than that of lead patented stock.

Since ordinarily all of the patented rod is drawn further, the drawability is of a great importance.

The tensile strength and reduction of area of drawn wire are shown in Fig. 10. The wire rod used in the drawing experiment was of grade SWRH 62A, 5.5 $\mathrm{mm}$ in diameter, and patented both by the fluidized bed method and in a lead bath.



Once again, the results in terms of tensile strength and reduction of area were identical for the both stocks indicating that the fluidized bed patenting can easily be substituted for lead patenting for this purpose.

\section{Further Comparison with Conventional Methods \\ (Especially Compared with Lead Patenting)}

A comparison of the fluidized bed patenting and lead patenting is shown in Table 3 . It is natural that healthy working conditions and freedom from noxious gas emissions can be attained by replacing the lead patenting with the fluidized bed patenting.

Moreover, it is worth noticing that lower manufacturing costs, reduced floor space, and better surfaces, among others, are additional good qualities achievable by the fluidized bed patenting instead of lead patenting. As described in $I I I$, the properties of stocks patented in a fluidized bed are the same as those of stocks patented conventionally, and the production cost of the former is less than that of the latter.

\section{Summary}

In our studies of the fluidized bed patenting process, using zircon sand as fluidized particles, we have come to the following conclusions with respect to cooling characteristics in the fluidized bed and mechanical properties of wire rod and wire patented by this method:

(1) The heat transfer coefficient of the fluidized bed is affected by an air velocity, the surface scale condition and the distance from the distributor. The value of the coefficient is about $670 \mathrm{kcal} /\left(\mathrm{m}^{2} \cdot \mathrm{hr} \cdot{ }^{\circ} \mathrm{C}\right)$ in the range of an air velocity of $12 \mathrm{~cm} / \mathrm{sec}$.

(2) Excellent mechanical properties at least as good as those achieved by lead patenting can be obtained by optimization of such factors as fluidized bed temperature, air velocity, and immersion time in

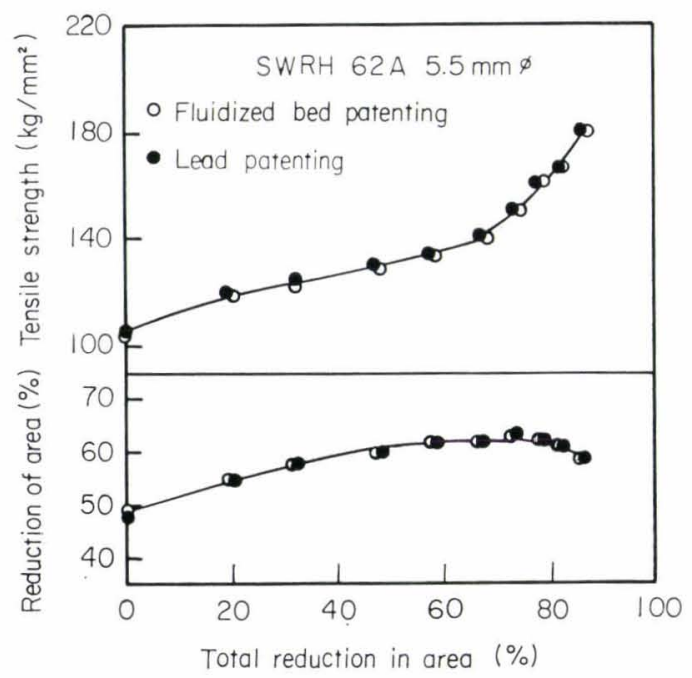

Air velocity $\quad: 12 \mathrm{~cm} / \mathrm{sec}$

Fluidized bed temperature $\quad: 300^{\circ} \mathrm{C}$ Immersion time in fluidized bed: $12 \mathrm{sec}$

Fig. 10. Mechanical properties of drawn wires 
Table 3. Comparative features of fluidized bed patenting and lead patenting

\begin{tabular}{|c|c|c|}
\hline & Fluidized bed patenting & Lead patenting \\
\hline $\begin{array}{l}\text { Safety and effect on } \\
\text { environment: }\end{array}$ & $\begin{array}{l}\text { Although particles used as cooling medium are } \\
\text { liable to cause air pollution, this can be com- } \\
\text { pletely averted by shielding the bed and employ- } \\
\text { ing dust collector. }\end{array}$ & $\begin{array}{l}\text { It is necessary to protect works from lead poison- } \\
\text { ing due to lead containing fumes. Disposal of } \\
\text { molten lead, removal of lead oxide, etc., result in } \\
\text { hazardous working conditions. }\end{array}$ \\
\hline Cost : & $\begin{array}{l}\text { The quantity of the sand taken out by the work } \\
\text { stock is nearly zero. Extremely small quantity } \\
\text { of sand is consumed during operation in the dust } \\
\text { collected with dust collector. } \\
\text { This can save about } ¥ 600 / \mathrm{t} \text { in costs compared to } \\
\text { lead patenting, based on output of } 2400 \mathrm{t} / \text { month. }\end{array}$ & $\begin{array}{l}\text { Lead adheres to the surface of the work stock and } \\
\text { is taken out in considerable amounts. There- } \\
\text { fore, the running cost in lead patenting is higher } \\
\text { than that in fluidized bed patenting. }\end{array}$ \\
\hline Length of bath: & $\begin{array}{l}\text { Length of bath is determined on the basis of time } \\
\text { required to complete transformation of the work } \\
\text { stock, so that bath length is only one-third or } \\
\text { one-fourth as long as that in lead patenting. }\end{array}$ & $\begin{array}{l}\text { Length of bath is determined on the basis of calorie } \\
\text { balance so that bath length is rather long. }\end{array}$ \\
\hline Range of application: & $\begin{array}{l}\text { Heat transfer coefficient of the bed is one-fifth as } \\
\text { much as that of molten lead so that heat-treat- } \\
\text { ment at relatively low temperatures is possible. } \\
\text { Treatment of work stock from } 1 \mathrm{~mm} \text { to } 11 \mathrm{~mm} \text { in } \\
\text { diameter is possible. }\end{array}$ & $\begin{array}{l}\text { The high heat transfer coefficient of lead enables } \\
\text { the treatment of relatively large diameter work } \\
\text { stock. }\end{array}$ \\
\hline Quality of work stock: & $\begin{array}{l}\text { Fluidized bed permits excellent uniformity in bath } \\
\text { temperature; variations from the set temperature } \\
\text { can be controlled within } \pm 10^{\circ} \mathrm{C} \text { and even } \pm 1^{\circ} \mathrm{C} \\
\text { if desired. The work stock is stable in quality. }\end{array}$ & $\begin{array}{l}\text { Without a stirrer, uniformity in bath temperature } \\
\text { can not be secured. } \\
\text { Especially near work stock entrance, temperature } \\
\text { reach about } 50^{\circ} \mathrm{C} \text { higher than elsewhere. This } \\
\text { means less stability in work stock quality. }\end{array}$ \\
\hline $\begin{array}{l}\text { Surface condition of } \\
\text { work stock: }\end{array}$ & $\begin{array}{l}\text { The hard oxide particles give excellent surface } \\
\text { condition on the work stock because they do not } \\
\text { interact with or adhere to the stock. }\end{array}$ & $\begin{array}{l}\text { Lead adhering to the surface of work stock is liable } \\
\text { to cause troubles in subsequent processes. }\end{array}$ \\
\hline Working temperature: & $\begin{array}{l}\text { A wide range of working temperatures is possible } \\
\text { because there is no limit from solidifying point. } \\
\text { Easily applicable to tempering and bluing treat- } \\
\text { ment. }\end{array}$ & $\begin{array}{l}\text { Working temperature range is normally as narrow } \\
\text { as } 400^{\circ} \text { to } 650^{\circ} \mathrm{C} \text {. } \\
\text { The lower limit depends on the melting point. }\end{array}$ \\
\hline
\end{tabular}

the fluidized bed.

(3) Keeping the air velocity constant at a stable condition for fluidization and setting the immersion time according to the stock diameter, desired mechanical properties are obtained by means of changing the fluidized bed temperature.

(4) Fluidized bed patenting can be successfully applied to stock from 1.0 to $11.0 \mathrm{~mm}$ in diameter.

(5) The drawability of stocks patented in the fluidized bed is the same as that of lead patented stocks.

Thus, it can be said that the fluidized bed patenting can readily be substituted for the lead bath patenting, thereby avoiding pollution problems and environmental hazards to plant hygiene, usually associated with the latter.

On the basis of the test results described above, the fluidized bed No. 1 equipment has been installed and operated successfully in a commercial scale.

\section{REFERENCES}

1) R. Sinclair, J. C. J. Wright and C. G. Tomas: JISI, 203 (1965), 131.

2) A. Jacob and G. L. Osberg: Can. J. Chem. Eng., 35 (1957), 5 .

3) A. P. Baskakov, V. Ya. Zukov, S. V. Grachev and V.S. Vershinia: Stal in Eng., (1964), No. 7, 574.

4) R.J. Stott: Wire Industry, 36 (1969), No. 426, 521.

5) R. W. Reynoldson and M. J. Virr: Wire Industry, 39 (1972), No. $467,918$.

6) V. Ya. Zukov, A. P. Baskakov, S. V. Grachev, G. K. Malikov and A. S. Zavarov: Stal in Eng., (1965), No. 7, 586.

7) N. Yamakoshi, T. Kaneda, A. Suzuki, E. Niina, Y. Yanagi and N. Hatsuoka: Tetsu-to-Hagané, 58 (1972), 1969.

8) T. Shirai: Kagaku Kogaku, 29 (1965), 928.

9) E. Wicke and F. Fetting: Chemie-Ingenieur-Technik, 26 (1954), 301.

10) G. Van Heerden, P. Nobel and D. W. Van Krevelen: Chem. Eng. Sci., 1 (1951), 51.

11) W. M. Dow and M. Jacob: Chem. Eng. Sci., 47 (1951), 637. 